\title{
Characteristics of Body Heat Balance of Paraplegics during Exercise in a Hot Environment
}

\author{
Masahiro Yamasaki ${ }^{1)}$, Kyu Tae Kim ${ }^{1)}$, Seung Wook Choi ${ }^{2)}$, Satoshi Muraki ${ }^{3)}$, \\ Mitsuhisa Shiokawa ${ }^{4)}$ and Takashi Kurokawa ${ }^{5)}$ \\ 1) Department of Health Science, Hiroshima University \\ 2) Department of Physical Education, Kyung Hee University, Seoul, Korea \\ 3) Department of Nutrition and Health Science, Siebold University of Nagasaki \\ 4) Department of Physical Therapy, Hiroshima Prefectural College of Health Sciences \\ 5) Department of Health and Sports Scieces, Hiroshima University
}

\begin{abstract}
The purpose of this investigation was to clarify the characteristics of body temperature regulation in paraplegics due to spinal cord injury (SCI) during an arm cranking exercise in a hot environment. Twelve paraplegics with lesions located between Th3 and L1,2 and seven able-bodied subjects (AB) participated in this study. The subjects were exposed to a hot $\left(33^{\circ} \mathrm{C}\right)$ or a moderate temperature $\left(25^{\circ} \mathrm{C}\right)$ environment for one hour and during the last 10 min of the exposure, the subjects performed arm cranking exercises at an exercise intensity of $40 \mathrm{~W}$. The skin temperatures at the chest, the upper arm, the thigh and the calf, the tympanic membrane temperature (Tty), and the skin blood flow of the thigh (SBFT) were continuously monitored during the experiment. Although no systematical variation was found in the Tty at $25^{\circ} \mathrm{C}$, the Tty at $33^{\circ} \mathrm{C}$ in paraplegics during exercise was significantly greater than that at rest $(\mathrm{P}<0.01)$, which indicated a pronounced heat stress for paraplegics at $33^{\circ} \mathrm{C}$. SBFT of paraplegics with high lesions of the SCI remained unchanged during the experiment at $25^{\circ} \mathrm{C}$ and $33^{\circ} \mathrm{C}$, while paraplegics with low lesions in this study showed consecutive increases in SBFT during exercise in both environmental conditions similar to AB. The increased core temperature in paraplegics with high lesions was considered to be due to a lack of sweat response and vasomotor activity in the paralyzed area. On the basis of the findings in this study, it can be suggested that high core temperature without any increment of SBFT may be characterized as body heat balance of paraplegics with high lesions during exercise in a hot environment. $J$ Physiol Anthropol 20 (4): 227-232, 2001 http:// www.jstage.jst.go.jp/en/
\end{abstract}

Keywords: spinal cord injury, arm cranking exercise, heat exposure, skin blood flow, tympanic membrane temperature

\section{Introduction}

In general, the core temperature of paraplegics due to spinal cord injury (SCI) increases significantly more than that of able-bodied persons during exercise and heat exposure (Attia and Engel, 1983; Downey et al., 1973, 1976; Fitzgerald et al., 1990; Gass and Camp, 1984; Gass et al., 1988; Guttmann, 1976; Sawka et al., 1989; Yamasaki et al., 2000). The increase in core temperature of a paraplegic is approximately dependent upon the level of the SCI (Gerner et al., 1992; Muraki et al., 1995; Petrofsky, 1992; Yamasaki et al., 2000). Basically there are no sweat responses (Freund et al., 1984; Normell, 1974; Tam et al., 1978) and no vasomotor activity (Normell, 1974) in the paralyzed area, so that heat loss from a paraplegic is disturbed according to the level of the SCI. Therefore, the higher the level of the SCI, the more the core temperature increases during exercise and heat exposure.

In our previous investigation (Muraki et al., 1996b), we demonstrated the importance of skin blood flow of the paralyzed area on body temperature regulation in paraplegics. During submaximal exercise (Muraki et al., 1995, 1996b) and even maximal exercise (Muraki et al., 1996a), no increase in skin blood flow of the thigh (SBFT) was found in paraplegics with lesions at or above Th12 irrespective of the exercise intensity. However, SBFT in paraplegics with lesions below L1 increased proportionally with the increase in exercise intensity, if the tympanic membrane temperature (Tty) exceeded a threshold temperature of $36.69^{\circ} \mathrm{C}$ (Muraki et al., 1996b). In contrast, 
paraplegics with high lesions showed comparatively greater Tty without any increase in SBFT (Muraki et al., 1996b). SBFT in the paralyzed area, therefore, can be considered to be very important for heat loss from paraplegics during exercise.

In our recent study (Yamasaki et al., 2000), we also investigated whether body temperature during heat exposure promoted SBFT in paraplegics. Paraplegics with high lesions between Th6 and Th10 showed no significant increase in SBFT, whereas paraplegics with lesions at Th11 or Th12 showed increased SBFT in a hot environment. The Tsk of the thigh increased with the time of exposure for all paraplegics. The increase in Tsk of the thigh in paraplegics with low lesions was due to increased SBFT, while in paraplegics with high lesions it was considered attributable to heat transfer from the environment to the skin. Since the relation between SBFT and Tsk of the thigh was significant for both groups, SBFT in paraplegics with high lesions might be affected by the increased Tsk of the thigh. These findings suggested that the response of body temperature and SBFT in paraplegics during a heat exposure was not necessarily the same as that during exercise. It is not clear how a combination of heat exposure and exercise affects the body heat balance in paraplegics.

The present study, therefore, examined the characteristics of body temperature regulation in paraplegics exposed to a hot environment during exercise. We focused here on the level of the SCI and SBFT in relation to body heat balance.

\section{Materials and Methods}

\section{Subjects}

The physical characteristics of the twelve male paraplegics with complete lesions who volunteered to participate in this study are shown in Table 1. The seven able-bodied men $(\mathrm{AB})$ who served as control subjects ranged in age from 22 to 48 years (mean 31.2 years), in height from 164 to $184 \mathrm{~cm}$ (mean $171.5 \mathrm{~cm}$ ), and in body mass from 63.2 to $79.5 \mathrm{~kg}$ (mean $67.8 \mathrm{~kg}$ ). No subject had any cardiovascular, metabolic, or pulmonary disease. Written informed consent was obtained from all subjects before their participation in this study.

\section{Testing protocols}

The subject, wearing a T-shirt and shorts, remained seated in his wheelchair or a chair for 1 hour at an ambient temperature $(\mathrm{Ta})$ of $25^{\circ} \mathrm{C}$ and a relative humidity (Rh) of 50\%. After that, the subject remained in the same room at $25^{\circ} \mathrm{C}$ for 1 hour or was immediately moved to a climatic chamber heated to Ta of $33^{\circ} \mathrm{C}$ and Rh of $50-55 \%$. The subject was exposed to the hot environment for one hour sitting in his wheelchair or a chair. During the last 10 minutes of the exposure at $25^{\circ} \mathrm{C}$ or $33^{\circ} \mathrm{C}$, the subject
Table 1. Characteristics of paraplegics

\begin{tabular}{cccccc}
\hline & $\begin{array}{c}\text { Age } \\
\text { (years) }\end{array}$ & $\begin{array}{c}\text { Body mass } \\
(\mathrm{kg})\end{array}$ & $\begin{array}{c}\text { Height } \\
(\mathrm{cm})\end{array}$ & $\begin{array}{c}\text { Time since } \\
\text { injury (years) }\end{array}$ & $\begin{array}{c}\text { Level of } \\
\text { Injury }\end{array}$ \\
\hline A & 41 & 51 & 172 & 26 & Th3 \\
B & 34 & 54 & 163 & 15 & Th6 \\
C & 33 & 42 & 163 & 8 & Th6 \\
D & 47 & 45 & 160 & 22 & Th7, \\
E & 43 & 65 & 176 & 6 & Th10 \\
F & 44 & 69 & 176 & 20 & Th11 \\
G & 26 & 61 & 182 & 2 & Th11 \\
H & 51 & 54 & 164 & 13 & Th12 \\
I & 29 & 58 & 170 & 7 & Th12 \\
J & 36 & 48 & 164 & 19 & Th12, L1 \\
K & 46 & 54 & 170 & 18 & L1 \\
L & 38 & 53 & 167 & 13 & L1, 2 \\
\hline
\end{tabular}

performed the arm cranking exercise at an exercise intensity of $40 \mathrm{~W}$ (50 rpm) using a mechanically-braked arm cranking ergometer (Monark Rehab Trainer model 881E) in the seated position.

Experiments were conducted during July, August and September when the subjects should have been naturally heat acclimated. Each subject was tested at the same time of day between 13:00 and 16:00 hour to minimize the possibility of circadian rhythm effects. The subject was asked to refrain from eating and drinking during the 2 hours immediately preceding the experiments.

\section{Physiological variables}

Tsk at 5 sites (chest, upper arm, thigh and calf) were measured once every minute using a thermocouple. Tty was recorded once every 5 minutes using an infrared thermometer (FirstTemp Genius 3000A, Sherwood Medical, St. Louis, USA).

SBFT was continuously monitored using a laser-Doppler flowmeter (ALF 21, Advance Co., Tokyo, Japan). The laser-Doppler probe was attached at the center of the anterior thigh near the measuring position of Tsk. The laser signals were recorded by a digital printer (ALF-P1, Advance Co., Tokyo, Japan). The time interval of measurement was set at 1 minute.

\section{Statistical analysis}

The last recordings during rest and exercise at each ambient temperature were utilized for data analysis for paraplegics and $\mathrm{AB}$. The means and standard deviations were calculated for all variables in $\mathrm{AB}$. The Wilcoxon test was used for comparison of Tsk and Tty at rest and during exercise. All P values less than 0.05 were considered significant.

\section{Results}

Figure 1 shows the Tsk of the chest at $33^{\circ} \mathrm{C}$ in each 
paraplegic and $\mathrm{AB}$ at rest and during exercise. There was a wide variation in the absolute values reached by different individuals, but they all showed the same Tsk at rest and during exercise.

The Tsk of the thigh at $33^{\circ} \mathrm{C}$ are illustrated in Fig. 2 . Subjects A (Th3), B (Th6) and C (Th6) showed greater Tsk at the thigh than other subjects. Moreover, although seven of the twelve paraplegics showed higher Tsk at the thigh during exercise than that at rest, the most marked difference was found in these three paraplegics. The difference between Tsk at the thigh at rest and during exercise was significant in paraplegics $(\mathrm{P}<0.05)$. In addition to the Tsk at the thigh, significant differences in the Tsk at the abdomen and calf between rest and exercise were found in paraplegics $(\mathrm{P}<0.05)$.

Figure 3 represents the Tty at $25^{\circ} \mathrm{C}$ at rest and during exercise. Although several subjects showed increased Tty during exercise compared with those at rest, no systematic differences related to the level of the SCI were found. Furthermore, the difference between rest and exercise in paraplegics was not significant. However, at $33^{\circ} \mathrm{C}$, the Tty during exercise was significantly greater than those at rest in all paraplegics and $\mathrm{AB}$ as shown in Fig. $4(\mathrm{P}<0.05)$. When compared with the Tty at $25^{\circ} \mathrm{C}$, Tty at $33^{\circ} \mathrm{C}$ was higher at rest and during exercise in all paraplegics.

The response pattern of SBFT during exercise at $25^{\circ} \mathrm{C}$ was fundamentally dependent on the level of the SCI. Figure 5 shows the time course of SBFT during exercise in paraplegics and the mean values of $\mathrm{AB}$. In subjects $\mathrm{F}$ to $\mathrm{L}$ and all $\mathrm{AB}$, a clear increase in SBFT was observed during exercise. In contrast, no increase in SBFT was found in subjects B, C, and D. Although SBFT slightly increased during the first 2 minutes compared with the resting value in subjects $A$ and $\mathrm{E}$, there was no further increase in SBFT.

At $33^{\circ} \mathrm{C}$, SBFT increased markedly and continuously during exercise in subjects $\mathrm{F}, \mathrm{G}, \mathrm{K}$, and $\mathrm{L}$ similar to that of AB (Fig. 6). Although subjects E, H, I, and J also showed increased SBFT during exercise, the extent of the increase was less compared with AB. Subjects A, B, C, and $\mathrm{D}$ showed no increase in SBFT regardless of the exercise time.

Figure 7 shows the relationship between SBFT and Tty at $25^{\circ} \mathrm{C}$. The findings used in this figure were the final values in all paraplegics and the mean final values in the $\mathrm{AB}$ group during exercise. In this figure, the paraplegics are divided in two groups according to the response of SBFT. One group consisted of subjects A to E who showed little or no increase in SBFT and the other subjects $\mathrm{F}$ to $\mathrm{L}$ showed clear increase in SBFT. No specific correlation was found between Tty and SBFT at $25^{\circ} \mathrm{C}$. In contrast to the measurements at $25^{\circ} \mathrm{C}$, at $33^{\circ} \mathrm{C}$ a relationship between SBFT and Tty were different among three groups as shown in Fig. 8. In subjects with an injury level between Th3 and Th10, SBFT was low despite the higher

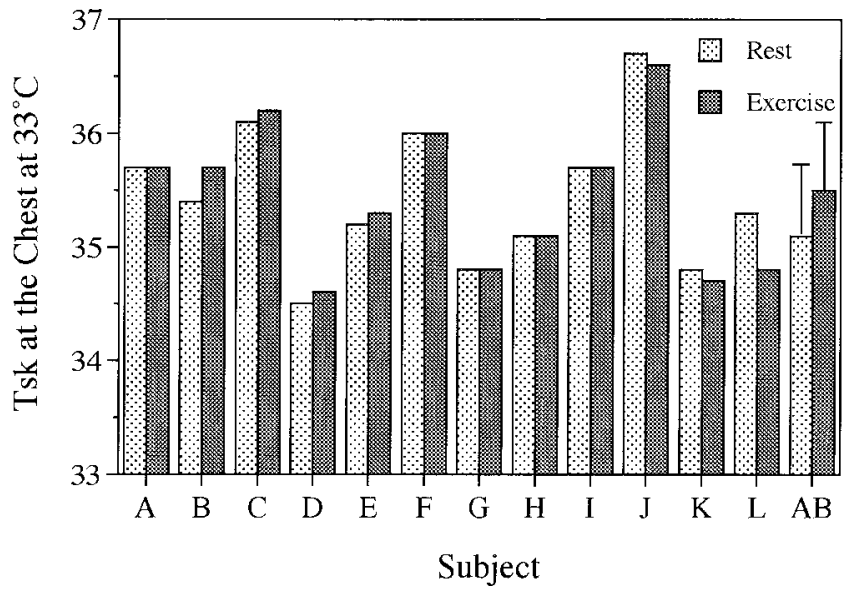

Fig. 1. The skin temperature (Tsk) at the chest at $33^{\circ} \mathrm{C}$ ambien room temperaturer at rest and during exercise in each paraplegic and $\mathrm{AB}$. The vertical lines represent +1 standard deviation in $\mathrm{AB}$.

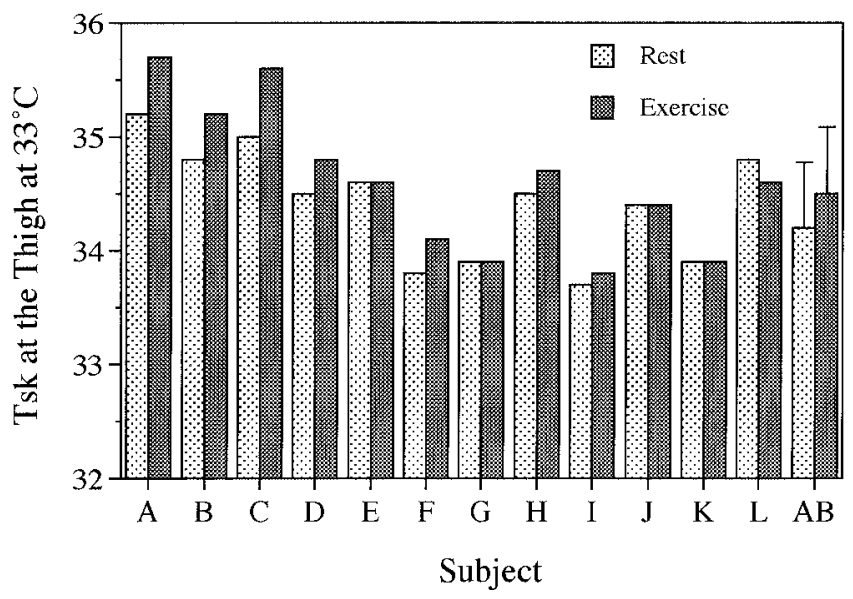

Fig. 2. The skin temperature (Tsk) at the thigh at $33^{\circ} \mathrm{C}$ ambient room temperature at rest and during exercise in each paraplegic and $\mathrm{AB}$. The vertical lines represent +1 standard deviation in $\mathrm{AB}$.

Tty. However, paraplegics with an injury level of Th11 to L1, 2 and AB showed a higher SBFT with lower Tty in comparison to paraplegics with an injury level of Th3 to Th10.

\section{Discussion}

The chest site where Tsk was measured in this study was not paralyzed in any paraplegics. This means that sweating and vasomotor activity in the chest remained intact. Therefore, the Tsk of the chest during exercise at $33^{\circ} \mathrm{C}$ exhibited a similar response to that at rest, because heat loss by sweating in this area was adequate to prevent an increase in the Tsk at the chest. However, the Tsk at the thigh at $33^{\circ} \mathrm{C}$ was higher in subjects $\mathrm{A}, \mathrm{B}$ and $\mathrm{C}$ than 


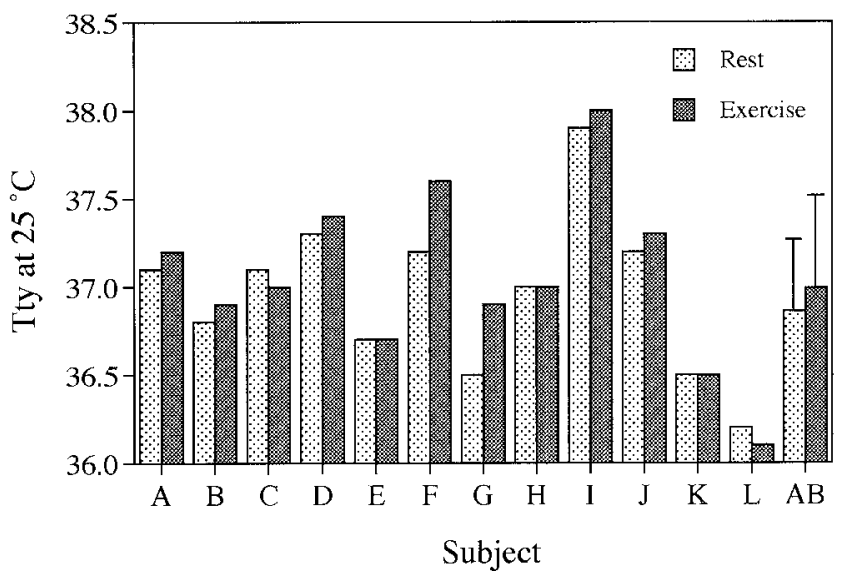

Fig. 3. The tympanic membrane temperature (Tty) at $25^{\circ} \mathrm{C}$ ambient room temperature at rest and during exercise in each paraplegic and $\mathrm{AB}$. The vertical lines represent +1 standard deviation in $\mathrm{AB}$.

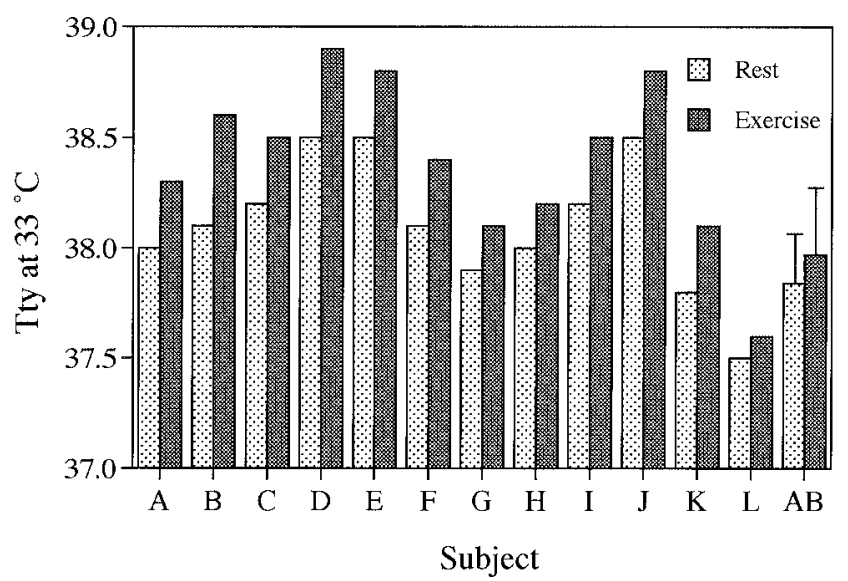

Fig. 4. The tympanic membrane temperature (Tty) at $33^{\circ} \mathrm{C}$ ambient room temperature at rest and during exercise in each paraplegic and $\mathrm{AB}$. The vertical lines represent +1 standard deviation in $\mathrm{AB}$.

the other subjects. The present findings disagree with those of Price and Campbell (1999) who found little change in Tsk at the thigh for paraplegics during exercise and attributed this to the loss of vasomotor control and reduced metabolic heat production in cool conditions at $21.5^{\circ} \mathrm{C}$. The present findings were in accordance with the findings of Yamasaki et al. (2000), who acknowledged increased Tsk at the thigh in paraplegics with high lesions in a hot environment $\left(33.5^{\circ} \mathrm{C}\right)$. These investigations showed that ambient temperature significantly affects the Tsk in the paralyzed area in a paraplegic. The increase in Tsk at the thigh for paraplegics with high lesions may demonstrate decreased sweating capacity and consequent heat storage (Price and Campbell, 1999).

The Tty at $33^{\circ} \mathrm{C}$ was much higher than that at $25^{\circ} \mathrm{C}$ both at rest and during exercise in paraplegics in the present

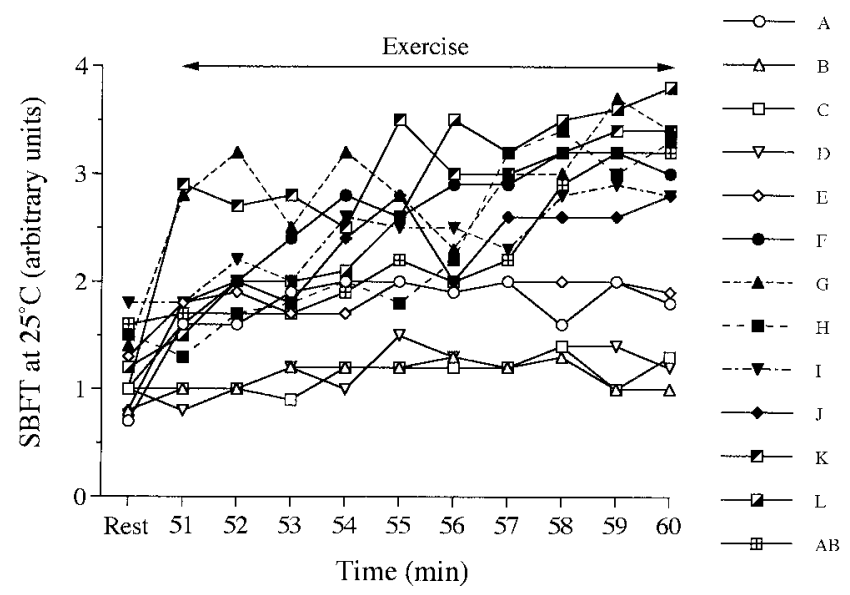

Fig. 5. Responses of skin blood flow of the thigh (SBFT) at $25^{\circ} \mathrm{C}$ ambient room temperature at rest and during exercise in each paraplegic and $\mathrm{AB}$.

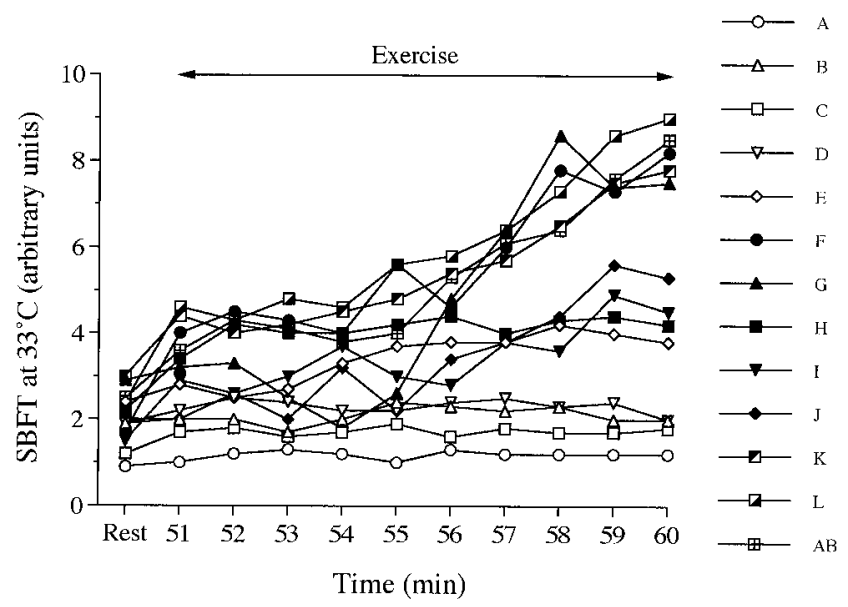

Fig. 6. Responses of skin blood flow of the thigh (SBFT) at $33^{\circ} \mathrm{C}$ ambient room temperature at rest and during exercise in each paraplegic and $\mathrm{AB}$.

study. Some studies reported that paraplegics suffer from a condition of partial pikilothermia which means the body temperature of paraplegics is largely dependent on ambient temperature (Attia and Engel, 1983; Downey et al., 1969; Pollock et al., 1951). Attia and Engel (1983) reported, under conditions beyond thermal neutrality, paraplegics possess a thermoregulatory set point which varies directly with ambient thermal conditions and this phenomenon is viewed as an adaptive thermoregulatory process following SCI.

No systematical variation was found in the Tty at $25^{\circ} \mathrm{C}$; that is, Tty is independent of the level of the SCI and physical activity. Meanwhile the Tty at $33^{\circ} \mathrm{C}$ in paraplegics during exercise was significantly greater than that at rest, which indicated pronounced heat stress for paraplegics at $33^{\circ} \mathrm{C}$. In general, exercise in a hot environment acceler- 


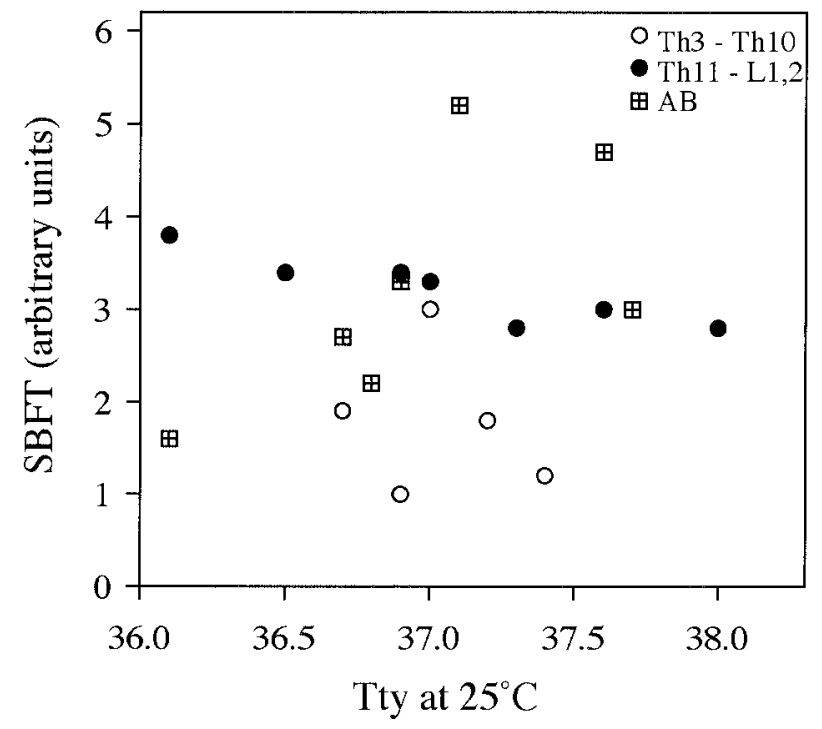

Fig. 7. Relationship between the skin blood flow of the thigh (SBFT) and the tympanic membrane temperature (Tty) at $25^{\circ} \mathrm{C}$ ambient room temperature.

ates the sweating response and vasodilation for heat loss from the body. In $\mathrm{AB}$, it has been demonstrated that skin blood flow is increased by cutaneous vasodilation to accelerate heat loss during dynamic exercise (Johnson and Rowell, 1975; Wenger et al., 1975; Kenney and Johnson, 1992). However, sweating response in a paraplegic is injured basically according to the level of the SCI (Huckaba et al., 1976; Normell, 1974; Silver et al., 1991; Tam et al., 1978). Furthermore, SBFT which can be regarded as an index of vasodilation in the thigh is also affected by the level of the SCI (Cooper et al., 1957; Freund et al., 1984; Muraki et al., 1995; 1996a, 1996b). Especially in paraplegics with high lesions, who have impaired sympathetic vasomotor function in the lower limbs, it has been suggested that skin blood flow is unchanged by exposure to a high temperature (Cooper et al., 1957; Guttmann et al., 1958; Yamasaki et al., 2000). In the present study, at both $25^{\circ} \mathrm{C}$ and $33^{\circ} \mathrm{C}$, paraplegics with high lesions also showed no increase in SBFT irrespective of the time duration of exercise. In this case, heat produced in the body was accumulated and caused a core temperature increase.

During exercise Muraki et al. (1996b) pointed out that SBFT in paraplegics with high lesions (Th6 to Th12) remained unchanged, while that in paraplegics with low lesions (T12 to L5) began to elevate markedly when the Tty exceeded a threshold temperature of $36.69^{\circ} \mathrm{C}$. In the present investigation, the Tty was already over $36.69^{\circ} \mathrm{C}$ in most subjects at $25^{\circ} \mathrm{C}$ and in all at $33^{\circ} \mathrm{C}$. For this reason, paraplegics with low lesions in the present study showed consecutive increases in SBFT during exercise.

Yamasaki et al. (2000) reported a significantly positive

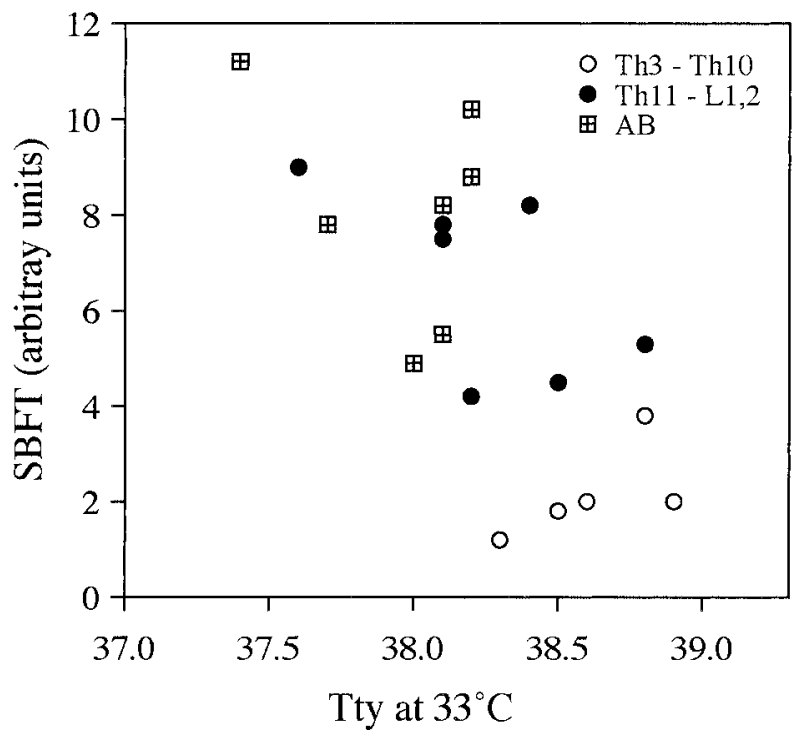

Fig. 8. Relationship between the skin blood flow of the thigh (SBFT) and the tympanic membrane temperature (Tty) at $33^{\circ} \mathrm{C}$ ambient room temperature.

relationship of SBFT to Tty in paraplegics with low lesions and $\mathrm{AB}$ at rest during heat exposure. This finding by Yamasaki et al. (2000) was obtained by continuous observation of SBFT and Tty in the time course of heat exposure. In the present study, we longitudinally analyzed the relation between Tty and SBFT using the last measurement during exercise in all subjects. The relationship between Tty at $33^{\circ} \mathrm{C}$ and SBFT was negative, as shown in Figure 8. Paraplegics with high lesions (Th3 to Th10) showed increased Tty with little increment in SBFT. In contrast, in AB, SBFT was significantly greater and Tty was lower than paraplegics with high lesions. The findings of paraplegics with low lesions were intermediate between paraplegics with high lesions and AB. These findings demonstrated that SBFT in the paralyzed area played an important role in body temperature regulation in paraplegics.

In conclusion, paraplegics with high lesions showed a greater core temperature without any increment in SBFT compared with those with low lesions and AB. Accordingly, heat loss by vasomotor activity in the paralyzed area was useful to maintain body heat balance in paraplegics. Since sweating is one of the most important factors for body temperature regulation in a hot environment and, moreover, is mainly dependent on the level of the SCI, sweating response should be measured in future research.

\section{References}

Attia M, Engel P (1983) Thermoregulatory set point in patients with spinal cord injuries (spinal man). 
Paraplegia 21: 233-248

Cooper KE, Ferres HM, Guttmann L (1957) Vasomotor responses in the foot to raising body temperature in the paraplegic patient. J Physiol 136: 547-555

Downey JA, Huckaba CE, Kelley PS, Tam HS, Darling RC, Cheh HY (1976) Sweating responses to central and peripheral heating in spinal man. J Appl Physiol 40: 701-706

Downey JA, Huckaba CE, Myers SJ, Darling RC (1973) Thermoregulation in the spinal man. J Appl Physiol 34: 790-794

Downey JA, Miller, JM, Darling RC (1969) Thermoregulatory responses to deep and superficial cooling in spinal man. J Appl Physiol 27: 209-212

Fitzgerald PI, Sedlock DA, Knowlton RG (1990) Circulatory and thermal adjustments to prolonged exercise in paraplegic women. Med Sci Sports Exerc 22: 629-635

Freund PR, Brengelmann GL, Rowell LB, Halar E (1984) Attenuated skin blood flow response to hyperthermia in paraplegic men. J Appl Physiol 56: 1104-1109

Gass GC, Camp EM (1984) Prolonged exercise response in trained male paraplegic men. Thermal Physiol 9: 429-432

Gass GC, Camp EM, Nadel ER, Gwinn TH, Engel P (1988) Rectal and rectal vs. esophageal temperatures in paraplegic men during exercise. J Appl Physiol 64: 2265-2271

Gerner HJ, Engel P, Gass GC, Gass EM, Hannich T, Feldmann G (1992) The effects of sauna on tetraplegic and paraplegic subjects. Paraplegia 30: 410-419

Guttmann L, Silver J, Wyndham CH (1958) Thermoregulation in spinal man. J Physiol 142: 406419

Huckaba CE, Frewin DB, Downey JA, Tam HS, Darling RC, Cheh HY (1976) Sweating responses of normal, paraplegic and anhidrotic subjects. Arch Phys Med Rehabil 57: 268-274

Johnson JM, Rowell LB (1975) Forearm skin and muscle vascular responses to prolonged leg exercise in man. J Appl Physiol 39: 920-924

Kenney WL, Johnson JM (1992) Control of skin blood flow during exercise. Med Sci Sports Exerc 24: 303-312

Muraki S, Yamasaki M, Ehara Y, Kikuchi K, Seki K (1996a) Effect of maximal arm exercise on skin blood flux in the paralyzed lower limbs in persons with spinal cord injury. Eur J Appl Physiol 74: 481-483

Muraki S, Yamasaki M, Ishii K, Kikuchi K, Seki K (1995)
Effect of arm cranking exercise on skin blood flow of lower limb in people with injuries to the spinal cord. Eur J Appl Physiol 71: 28-32

Muraki S, Yamasaki M, Ishii K, Kikuchi K, Seki K (1996b) Relationship between temperature and skin blood flux in lower limbs during prolonged arm exercise in persons with spinal cord injury. Eur J Appl Physiol 72: 330-334

Normell LA (1974) Distribution of impaired cutaneous vasomotor and sudomotor function in paraplegic man. Scand J Clin Lab Invest 33: 25-41

Petrofsky JS (1992) Thermoregulatory stress during rest and exercise in heat in patients with a spinal cord injury. Eur J Appl Physiol 64: 503-507

Pollock LJ, Boshes B, Chor H, Finkelman I, Arief AF, Brown N (1951) Defects of regulatory mechanisms of autonomic function in injuries to spinal cord. $J$ Neurophysiology 14: 85-93

Price MJ, Campbell IG (1999) Thermoregulatory responses of spinal cord injured and able-bodied athletes to prolonged upper body exercise and recovery. Spinal Cord 37: 772-779

Sawka MN, Latzka WA, Pandolf KB (1989) Temperature regulation during upper body exercise: able-bodied and spinal cord injured. Med Sci Sports Exerc 21: S132S140

Silver JR,Randall WC, Guttman L (1991) Spinal mediation of thermally induced sweating. J Neurol Neurosurg Psychiat 54: 297-304

Tam HS, Darling RC, Chen HY, Downey JA (1978) The dead zone of thermoregulation in normal and paraplegic man. Can J Physiol Pharmacol 56: 976-983

Wenger CB, Roberts MF, Stolwijk JAJ, Nadel ER (1975) Forearm blood flow during body temperature transients produced by leg exercise. J Appl Physiol 38: 58-63

Yamasaki M, Shiokawa M, Choi SW, Muraki S (2000) Effect of acute heat exposure on skin blood flow of the paralyzed thigh in persons with spinal cord injury. Spinal Cord 38: 224-228

Received: February 9, 2001

Accepted: April 16, 2001

Correspondence to: Masahiro Yamasaki, Department of Health Science, Hiroshima University, 1-7-1 Kagamiyama, Higashi-Hiroshima 739-8521, Japan

E-mail: yamasak@hiroshima-u.ac.jp 